\title{
O LUGAR: FATOR FUNDAMENTAL NO PROCESSO DE PROJETO. APRESENTAÇÃO DO ESTUDO DE CASO, PROJETO "UBS" EM RESISTÊNCIA, CHACOI ARGENTINA
}

\author{
EL LUGAR. FACTOR FUNDAMENTAL EN EL PROCESO DE DISEÑO. PRESENTACIÓN DEL CASO DE \\ ESTUDIO, PROYECTO “UBS" EN RESISTENCIA, CHACO, ARGENTINA
}

THE PLACE. FUNDAMENTAL FACTOR IN THE DESIGN PROCESS. PRESENTATION OF THE CASE STUDY, "UBS" PROYECT IN RESISTENCIA, CHACO, ARGENTINA

\section{MICELI, MELISA LOREDANA}

Faculdade de Arquitetura, Desenho e Urbanismo, Universidade de Buenos Aires. melisalmiceli@gmail.com

\section{CONESA, CARLOS MARTÍN PAGANO}

Faculdade de Arquitetura, Desenho e Urbanismo, Universidade de Buenos Aires. carlosmpagano@gmail.com

\section{COMPAGNONI, ANA MARIA}

Professora, Universidade de Buenos Aires, anacompa@terra.com.ar

\section{INTRODUÇÃO}

No âmbito da XI Bienal de Arquitetura Bioclimática "José Miguel Aroztegui", e sob as diretrizes acadêmicas propostas na matéria "Introdução à Arquitetura Bioclimática" do curso de Arquitetura da Faculdade de Arquitetura, Desenho e Urbanismo (FADU) da Universidade de Buenos Aires (UBA), se desenvolve o projeto "Unidade Básica de Saúde" na cidade de Resistencia, Chaco/ Argentina, premiado com terceiro lugar pelo júri da Bienal Aroztegui.

A proposta acadêmica consiste no estudo e análise das variáveis climáticas do local a fim de incluí-las no processo projetual, tomar decisões arquitetônicas que permitam um máximo de aproveitamento das mesmas e conseguir alcançar sensações de conforto térmico, sem a necessidade de utilizar demasiadamente energias convencionais, ou seja, otimizando seu uso.

Desse modo, apresenta-se o estudo de caso como mecanismo para refletir sobre o conceito de lugar, longe de entender o objeto arquitetônico como um edifício isolado. Interpretamos que o processo projetual envolve variáveis tanto de desenho funcional, quanto o meio natural e cultural com o qual este dialogará. Ao contrário de não levar em conta culturas regionais ao longo da história, sendo desvalorizadas e afastadas de seus territórios, este estudo de caso tem como propósito principal ressignificar valores regionais, próprios do local e potencializá-los em conjunto com as condições geográficas naturais do entorno.

Como objetivo, procura-se gerar uma arquitetura de acordo com o contexto, produto da incorporação do meio com seus aspectos naturais, fatores climáticos, recursos regionais e características socioculturais, desde o utópico e o modo de viver, até as técnicas construtivas. 


\section{PARTINDO DO CLIMA, ATÉ A ESSÊNCIA DO LUGAR}

\section{O lugar, seu clima}

A cidade de Resistencia ( $27^{\circ} 27^{\prime}$ Sul) se localiza sobre a planície aluvial do rio Paraná, a 50 metros acima do nível do mar, atravessada pelo tortuoso Rio Negro e com o grande número de lagoas. Seu clima é semitropical e semi-íngreme, sendo uma zona muito quente, com temperaturas máximas que oscilam entre os $20^{\circ} \mathrm{C}$ em Junho e os $33^{\circ} \mathrm{C}$ em Janeiro, com mínimas entre $10^{\circ} \mathrm{C} \mathrm{e} 21^{\circ} \mathrm{C}$, umidade relativa entre $60 \%$ e $90 \%$, e precipitações que vão desde os $50 \mathrm{~mm}$ em Julho a $285 \mathrm{~mm}$ em Abril, com o total de precipitação anual de $1550 \mathrm{~mm}$ (Serviço Meteorológico Nacional, 1992). Com a análise destas variáveis, se deduz que as condições de conforto térmico se dão nos meses de Junho a Setembro, enquanto que no resto do ano se diminui o conforto devido às altas temperaturas e umidade relativa do ambiente.

Figura 1: Variáveis climáticas. Temperatura, precipitações e umidade absolutas.

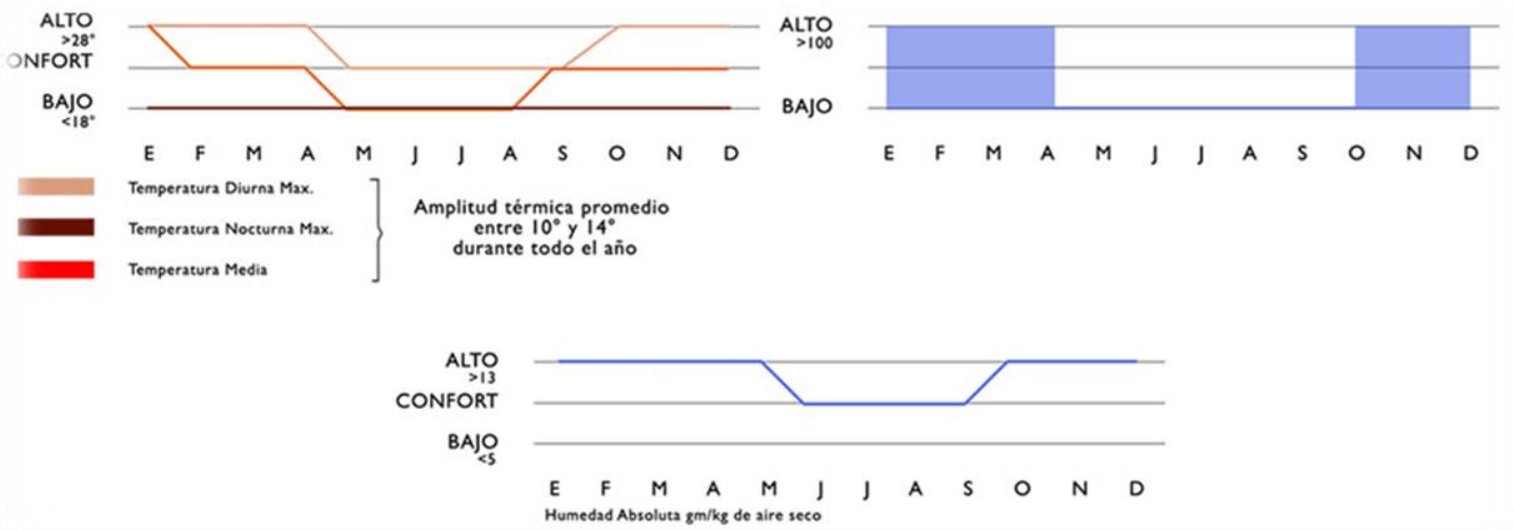

Fonte: Gráficos realizados pelos autores buscando analisar variáveis climáticas do local.

Após a análise das diferentes características climáticas que o local apresenta, na qual se implantaria o projeto e levando-se em consideração que a zona permite o uso e aproveitamento dos espaços exteriores, analisaram-se distintas estratégias para alcançar o conforto térmico no interior da UBS e condições térmicas agradáveis na praça de acesso e nos parques exteriores que compõem todo o projeto. Neste sentido, as decisões projetuais foram as seguintes:

- orientar a fachada principal para o norte e protegê-la com um sistema de pérgolas que tangencie e bloqueie o sol, segundo a estação do ano e horário de incidência;

- uso de materiais regionais com adequados coeficientes de transmissão térmica;

- tratamento da coberta para gerar correntes de ar, afastando o ar quente e permitindo a entrada de sol no solstício de inverno;

- projetar um sistema que permita utilizar a água da chuva até quatro vezes, mediante diferentes processos de filtração e purificação;

- utilizar painéis e tanques termo solares;

- uso da vegetação, não apenas como elemento paisagístico, mas também como elemento bioclimático.

A figura 2 mostra o entorno em que foi inserido o projeto e apresenta as diferentes estratégias bioclimáticas utilizadas no mesmo. 
Figura 2: Projeto UBS, perspectiva representativa.

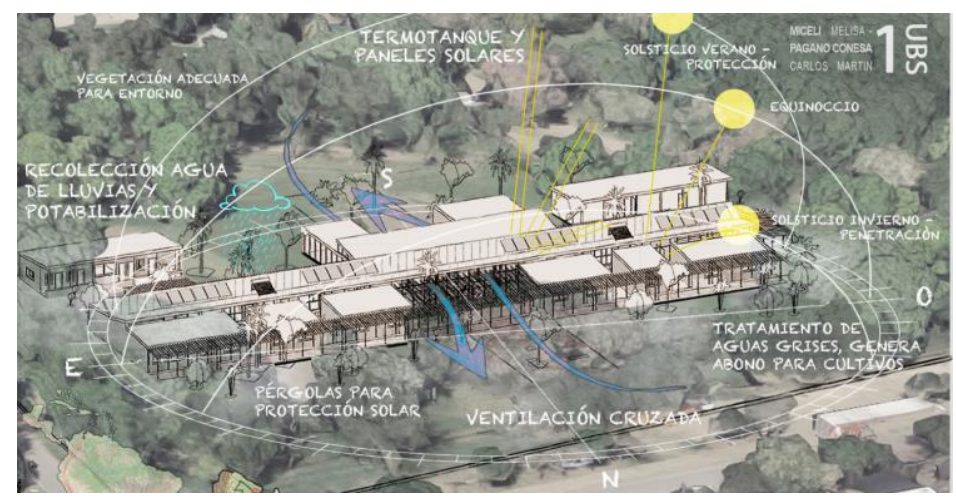

Fonte: Projeto dos autores ${ }^{1}$.

$\mathrm{Na}$ figura 3 está indicado o gráfico de análise da penetração solar em horários significativos - 9:00h, 12:00h e 15:00h - nos solstícios de verão e inverno e equinócios.

Figura 3: Cortes com penetração solar em espaços interiores.

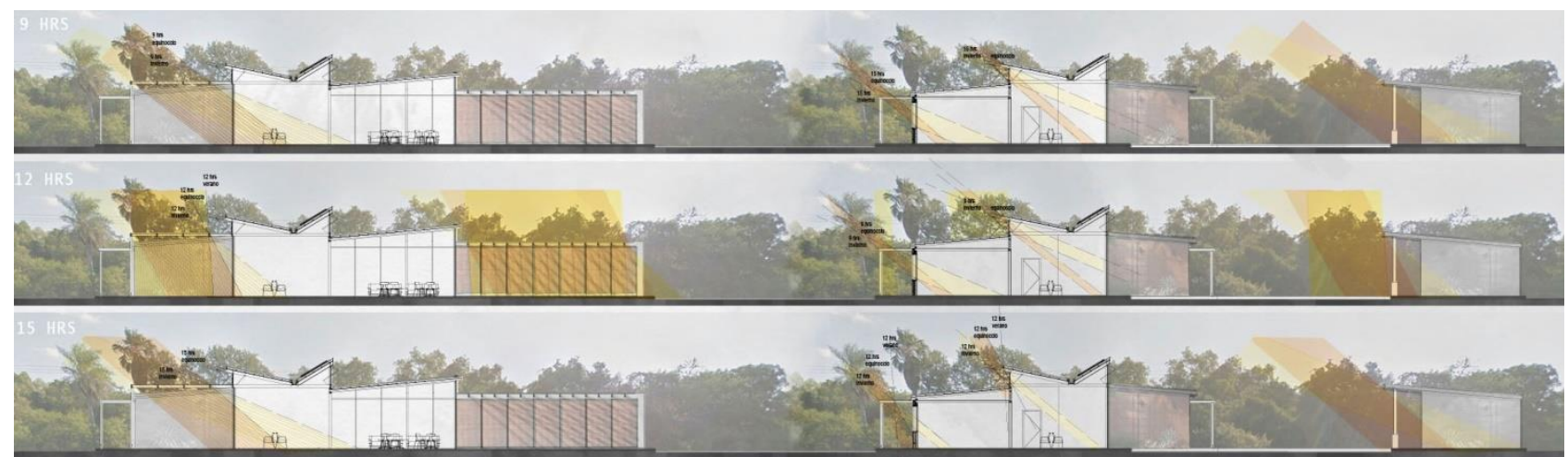

Fonte: Projeto dos autores.

Figura 4: Planta do projeto UBS.

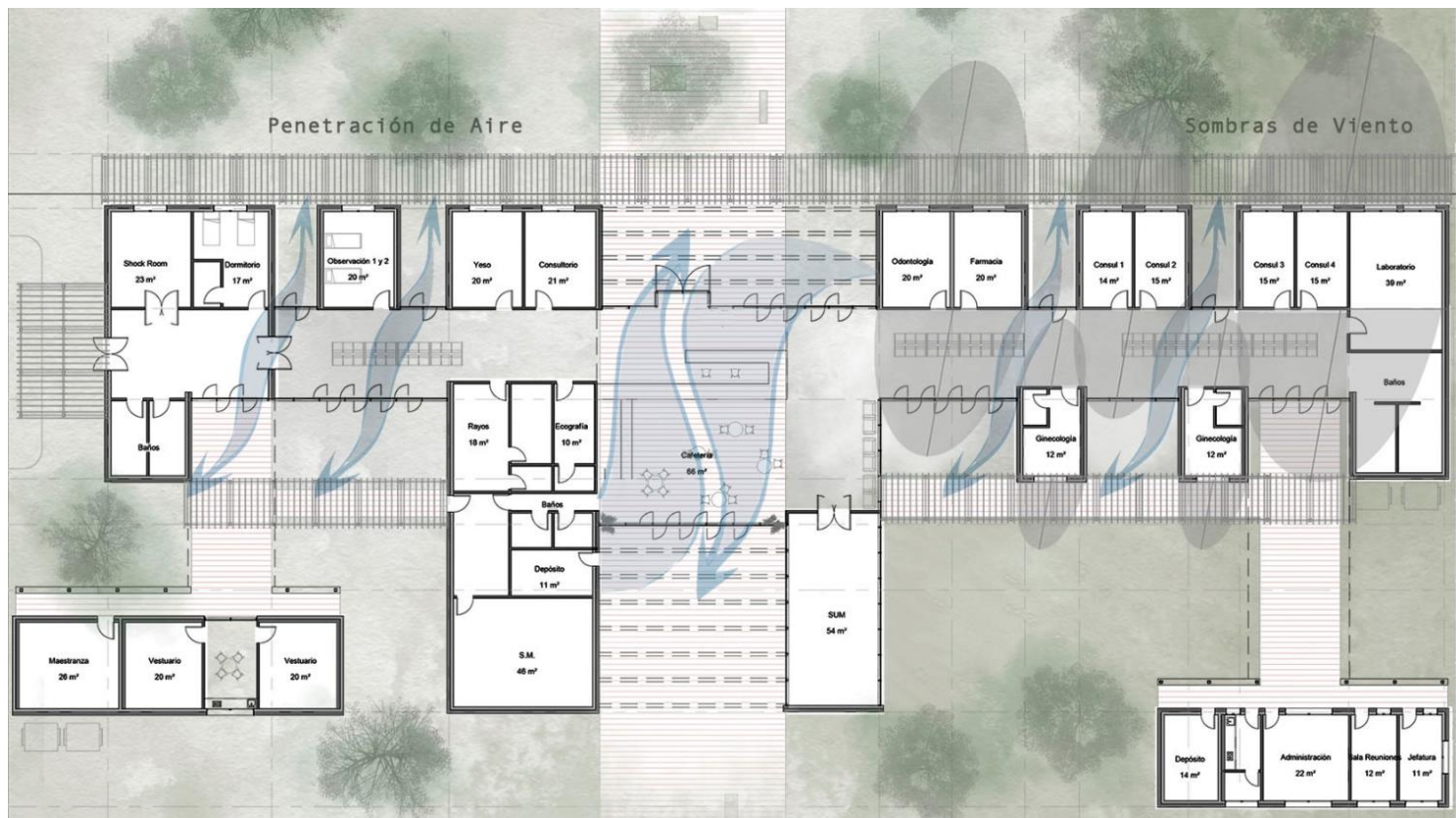

Fonte: Projeto dos autores. 
Ao tratar-se de um programa cujos usos devem manter uma lógica espacial determinada, procurou-se projetar fazendo com que o uso se relacione com a morfologia mais adequada para o aproveitamento dos fatores naturais bioclimáticos da região, que contribua com o conforto no interior da unidade. Assim, buscou-se articular o programa com pátios que permitam a renovação dos ares nas salas de espera e espaços de uso público. Se trata de um projeto que é fundamentalmente permeável, que busca gerar instâncias de transição desde o exterior até o interior e novamente ao exterior; fazendo uso da vegetação, não só como elemento paisagístico, bem como estratégia bioclimática que permita a passagem de ventilação e gere sombras. O espaço exterior é parte do projeto e conversa com a arquitetura, na qual se incluem passeios, áreas de repousos e de distração.

$\mathrm{Na}$ figura 4, mostra-se a organização espacial e os diferentes usos, como estratégias bioclimáticas que opta por fragmentar o programa e abrir sistematicamente a envoltória e permitir a ventilação cruzada necessária na área. O setor de segurança - $24 \mathrm{~h}$ - está orientado a oeste para aproveitar o ganho térmico nas horas da noite e a leste está o setor de consultório ambulatoriais.

Figura 5: Imagens do projeto UBS.

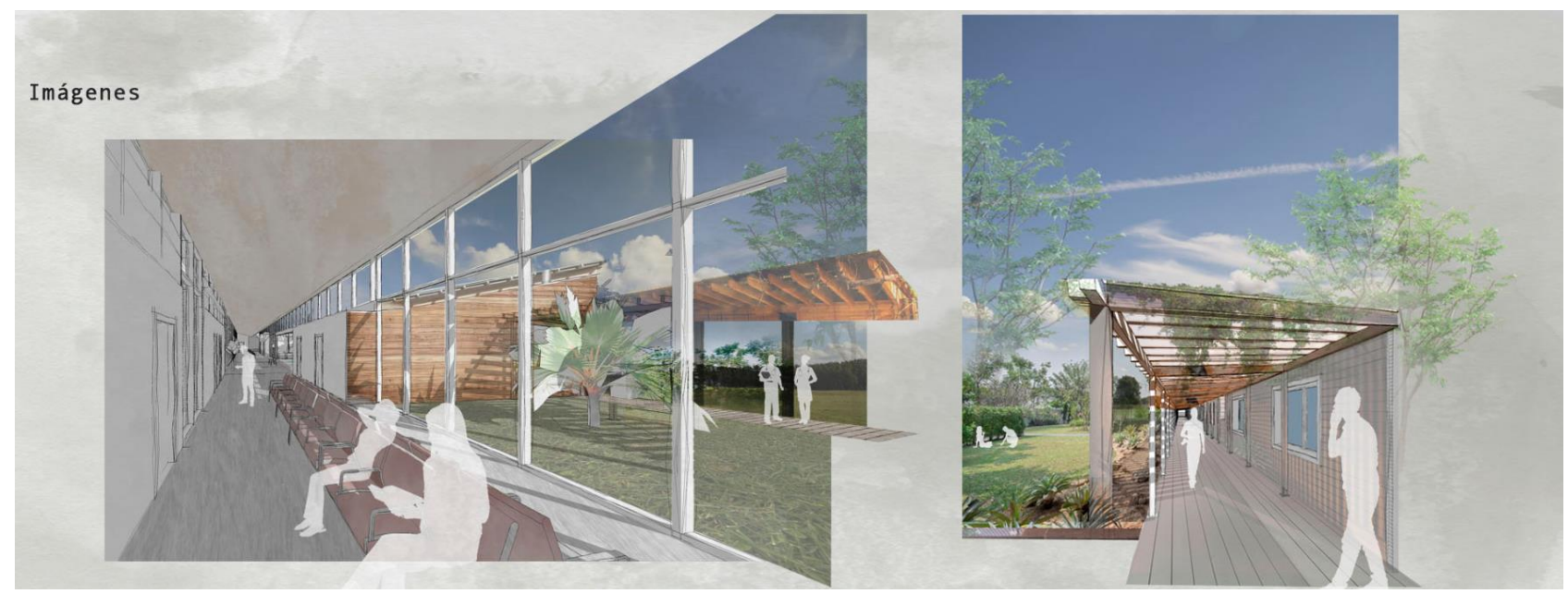

Fonte: Projeto dos autores.

\section{O lugar, sua cultura}

A primeira regra da sustentabilidade é pertencer culturalmente ao lugar, ao entorno onde está inserido (...) sem relação com o lugar, a cultura, o contexto onde se insere, há uma perda de essência na arquitetura (STEKAR, 2018, p. 309).

$\mathrm{Na}$ Argentina existem aproximadamente 23 mil comunidades indígenas com aproximadamente um milhão de habitantes. Na província de Chaco, a população ultrapassa 41 mil habitantes e, em geral, são povos originários dos setores da população que apresentam condições marginais, discriminação e exclusão.

Seguindo a "primeira regra de sustentabilidade" que levanta Stekar (2018), busca-se, por meio deste projeto arquitetônico e, a partir da reinterpretação e inclusão dos elementos originários de culturas indígenas da região do Chaco, principalmente QOM e MOQOIT, revalorizar estas culturas na cidade capital, Resistencia.

Entendemos que conhecer, estudar e internalizar respeito ao lugar, com todas suas características, sejam históricas, culturais, climáticas e geográficas, modelam o pensamento do projetista e ao próprio projeto que surge depois de entender o local e, em consequência, constituem uma arquitetura que questiona e dialoga com o seu entorno.

Para este projeto, estudaram-se as diversas culturas que convivem em Resistencia e na província, a história, e com ela, as condições sociais, também históricas, como viveram até atualmente os povos originais, seu habitat, suas tipologias de edificações e suas técnicas construtivas. Não podemos esquecer que, devido à constante marginalidade que sofrem através dos anos, são grupos sociais que se veem obrigados a resolver e auto administrar a falta de equipamentos, a construção de escolas e centros comunitários, os quais são elementos chaves para ensinar e transmitir suas culturas e, neste sentido, é de primeira ordem incluir reflexivamente ao projeto todos estes elementos que são sensíveis a sua base cultural e the dão identidade. 
Busca-se então, não apenas um funcionamento correto do edifício, como, dar valor e visibilidade a todos estes aspectos, entendendo o projeto como um agente ativo na produção das relações sociais e colocando o foco em tentar produzir uma transformação que reconstrua o tecido social. Acredita-se que os habitantes desta terra possuem valores fundamentais que devemos recuperar, como o conhecimento e compreensão do ambiente natural, o cuidado com ele e a construção com materiais locais, incluindo-os em cada projeto envolvido em um local,

O sentido do projeto se refere a relação deste com a realidade que o contém. Realidade que se constitui como um todo integrado e integrador consigo mesmo (...) determina as condições e o desenvolvimento do processo projetual (..) na medida que a arquitetura afeta a configuração do meio que se desenvolve, deverá entender-se que poucos aspectos deste Ihe são diferentes. Assim, mostra que a obra não se entende como uma entidade individual, mas que é considerado um formador de contexto (STEKAR, 2018, p.310).

Neste sentido, o objeto arquitetônico não só é "formador de contexto", se não for transformador e, a partir disto, nos compete a responsabilidade e o dever de conhecer, entender e fazer com que o processo projetual seja guiado e dirigido pelo lugar, sua essência e sua natureza, para que esta transformação seja positiva para o lugar e para evitar cair no que Fernández Alba menciona em seu discurso sobre a Natureza do Espaço que Constrói a Arquitetura:

...atualmente trabalhamos com arquitetos, em projetos de aparência, sem mais conteúdo (...) a dissociação levantada entre projeto como justaposição de partes geometricamente definidas de fácil identificação e espaço construído, origina um problema de distanciamento entre o modelo e a realidade... (FERNANDEZ ALBA, 1989, p. 16)

\title{
O lugar, as pessoas
}

Partimos da premissa, que em nossa opinião deveria estar presente em todos os projetos arquitetônicos, considerando como aspecto principal as pessoas do lugar, como seres orientadores fundamentais do projeto, já que se não fosse por e para eles, realizaríamos projetos vazios e carentes de sentido. Nesse contexto, acolhemos as reflexões do arquiteto Solano Benítez como nossas para conseguir construir um pensamento profundo a este respeito, que nos marca o caminho como arquitetos e como pessoas quando se referem ao bem-estar de uma comunidade e ao bem-estar comum.

\begin{abstract}
... minha humanidade começa quando entendo que no mínimo, "sou" "vocês"; minha unidade inicia nesse momento em que sou capaz de transferir meu "eu" a "ti", e cresce e se expande até tratar de ser "todos". Se "eu" "sou" "vocês", se "somos", como não posso me preocupar que estejas bem, que você finalmente "procure meu" bem, porque necessito que estejas bem, para estar bem. Se não posso fazer essa construção (..) nossa disciplina estaria cumprindo um mandato imperativo e necessário, velar pela vitalidade dos seres enquanto humanos...
\end{abstract}

As sociedades são boas a medida que as pessoas são boas, se não alcançarmos entender a profundidade do mandato disciplinar de construir a condição humana em exercício, logicamente, nosso trabalho se torna essencial e nosso campo de ação é importantíssimo porque completa esse "todo" que "somos" ...2

Stekar (2018) expressa que "se faz necessário descobrir e revelar a essência do lugar, como entendimento pleno na maneira de interagir no par arquitetura-contexto" (Stekar, 2018, p.311). A partir desta afirmação, é necessário ter em conta não só o conhecimento da história, das imagens que proveem o lugar, seus elementos físicos, topográficos e climáticos, como também os múltiplos e diversos elementos que se reconhecem a partir dos feitos culturais, os quais alimentam a essência do lugar e, por consequência, enriquecem ao projeto arquitetônico. Em sintonia com Benítez, temos que prestar especial atenção às pessoas que ali habitam e se desenvolvem, para que, como arquitetos, possamos outorgar-lhes projetos que contribuam com seu "bem-estar", para nós "estarmos bem".

\section{CONSIDERAÇÕES FINAIS}

O projeto UBS é realizado refletindo continuamente os vários aspectos desenvolvidos neste artigo e com a firme convicção de que a arquitetura, quando se considera todas as características que compõem o lugar, pode ter um papel social de transformação. Entendemos que, se o local e sua essência foram respeitados, integrando seus futuros usuários ao processo arquitetônico e, incorporando estratégias de projeto bioambiental, podemos obter um resultado mais inclusivo, relevante e respeitoso com o meio ambiente, com o lugar, com a natureza e com as pessoas para poder alcançar "aquilo tudo o que somos". 


\section{REFERENCIAS}

ATTÍAS, A. M. y LOMBARDO, R. D. Población originaria de la provincia del Chaco, dominación y resistencias. Theomai. n. 30. Quilmes 2014.

BOURDIEU, P. La miseria del mundo, Cap. Efectos del lugar. París, 1993.

EVANS J. M. Y de SCHILLER S., "Diseño Bioambiental y Arquitectura Solar", Ediciones Previas, EUDEBA, Buenos Aires, 1996.

FERNÁNDEZ ALBA, A. Sobre la naturaleza del espacio que construye la arquitectura. Madrid, 1989.

MARTÍN HERNÁNDEZ, M. Sobre el lugar en arquitectura. Historia y Teoría de la Arquitectura. n. 4-5, Sevilla, 2004. MUNTAÑOLA THORNBERG, J. La arquitectura como lugar. Barcelona, 1995.

SERVICIO METEOROLÓGICO NACIONAL, Estadísticas meteorológicas 1981-1990, Serie B № 37, n. 205-209. Buenos Aires, 1992.

STEKAR, J.G. La esencia, un planteo didáctico en la génesis proyectual. AREA Agenda de reflexión en arquitectura diseño y urbanismo. n. 24. Buenos Aires, 2018.

\section{NOTAS}

${ }^{1}$ Projeto desenvolvido para a materia Introdução ao Desenho Bioclimatico e apresentado no Concurso Estudantil Ibero-Americano de Arquitetura Bioclimática da XI Bienal José Miguel Aroztegui, publicado em http://bienalaroztegui.arq.ufsc.br/

NOTA DO EDITOR $\left(^{*}\right)$ O conteúdo do artigo e as imagens nele publicadas são de responsabilidade do(s) autor(es). 